This item was submitted to Loughborough's Research Repository by the author.

Items in Figshare are protected by copyright, with all rights reserved, unless otherwise indicated.

\title{
Gender dysphoria and autism spectrum disorder: a systematic review of the literature
}

PLEASE CITE THE PUBLISHED VERSION

http://dx.doi.org/10.1016/j.sxmr.2015.10.003

\section{PUBLISHER}

(C) International Society for Sexual Medicine. Published by Elsevier Inc.

\section{VERSION}

AM (Accepted Manuscript)

\section{PUBLISHER STATEMENT}

This work is made available according to the conditions of the Creative Commons Attribution-NonCommercialNoDerivatives 4.0 International (CC BY-NC-ND 4.0) licence. Full details of this licence are available at: https://creativecommons.org/licenses/by-nc-nd/4.0/

\section{LICENCE}

CC BY-NC-ND 4.0

\section{REPOSITORY RECORD}

Glidden, Derek, Walter P. Bouman, Beth Jones, and Jon Arcelus. 2019. "Gender Dysphoria and Autism Spectrum Disorder: A Systematic Review of the Literature”. figshare. https://hdl.handle.net/2134/20811. 
Gender Dysphoria and Autism Spectrum Disorder: A systematic review of the literature

\author{
Derek Glidden ${ }^{1}$, Walter Pierre Bouman ${ }^{1}$, Bethany Alice Jones ${ }^{1,2}$ and Jon Arcelus ${ }^{1,3}$ \\ ${ }^{1}$ Nottingham Centre for Gender Dysphoria, 3 Oxford Street, Nottingham NG1 5BH, UK. \\ ${ }^{2}$ School of Sport, Exercise and Health Sciences, Loughborough University, Loughborough, \\ Leicestershire, LE11 3TU, UK. \\ ${ }^{3}$ Division of Psychiatry and Applied Psychology, Faculty of Medicine \& Health Sciences, \\ University of Nottingham, Nottingham, United Kingdom
}

* Contact details: Dr Walter Pierre Bouman, Nottingham Centre for Gender Dysphoria, Nottinghamshire Healthcare NHS Trust, 3 Oxford Street, Nottingham NG1 5BH, UK. Tel. +44 115 8760160; E-mail: walterbouman@doctors.org.uk

Conflict of Interest: The authors report no conflicts of interest.

Funding: None.

\title{
Statement of Authorship
}

Category 1

(a) Conception and Design

Derek Glidden; Walter Pierre Bouman; Jon Arcelus

(b) Acquisition of Data

Derek Glidden; Jon Arcelus

(c) Analysis and Interpretation of Data

Derek Glidden; Walter Pierre Bouman; Jon Arcelus

Category 2

(a) Drafting the Article

Derek Glidden; Walter Pierre Bouman; Jon Arcelus; Bethany Alice Jones 
(b) Revising it for Intellectual Content

Derek Glidden; Walter Pierre Bouman; Jon Arcelus; Bethany Alice Jones

Category 3

(a) Final Approval of the Completed Article

Derek Glidden; Walter Pierre Bouman; Jon Arcelus; Bethany Alice Jones 


\section{ABSTRACT}

Introduction. There is a growing clinical recognition that a significant proportion of patients with Gender Dysphoria, have concurrent Autism Spectrum Disorder (ASD).

Aim. The purpose of this review is to systematically appraise the current literature regarding the co-occurrence of Gender Dysphoria and ASD.

Methods. A systematic literature search using Medline/Pubmed, PsycINFO and Embase were conducted from 1966 to July 2015.

Main Outcome Measures. A total of 58 articles were generated from the search. Nineteen of these publications met the inclusion criteria.

Results. The literature investigating ASD in children and adolescents with Gender Dysphoria have found a higher prevalence rate of ASD compared to the general population. There is a limited amount of research in adults. Only one study showed that adults attending services for Gender Dysphoria had increased ASD scores. Another study showed a higher proportion of atypical gender identity in adults with ASD.

Conclusions. Although the research is limited, especially with adults, there is an increasing amount of evidence that suggests a co-occurrence between Gender Dysphoria and ASD. Further research is vital for educational and clinical purposes.

Key Words. Gender Dysphoria; Transgender; Transsexualism; Autism; Autism Spectrum Disorder; systematic review, 


\section{Introduction}

Gender Dysphoria, a diagnostic term from the Diagnostic and Statistical Manual of Mental Disorders-version 5 (DSM-5) [1], is used to define individuals presenting with an incongruence between assigned and experienced gender. The diagnosis is characterised by a strong and persistent cross-gender identification, which is often associated with significant distress of one's own biological sexual characteristics and assigned social gender role. The International Classification of Diseases, edition 10, (ICD-10; World Health Organisation, 1992) describes the desire to live and be accepted as a member of the opposite sex as Transsexualism. Sometimes this gender incongruence is sufficiently intense that people undergo a transition to the opposite gender (usually from male to female or from female to male). This typically involves changes in social role and presentation, and may require prescription of cross-sex hormones and/or having gender related surgeries [2, 3, 4].

There are several different terms used within the literature to describe people who feel incongruence between their assigned sex at birth and gender identity, however throughout this review the terms "trans female" will be used to describe individuals assigned male at birth, based on their genital appearance, but later identify as female and "trans male" for people assigned female at birth, based on their genital appearance, but later identify as male.

Studies assessing prevalence rates of Gender Dysphoria in the general population are complex to undertake and most studies have examined trans people attending gender identity clinical services. As the majority of these studies have been conducted in Europe, they have adopted the International Classification of Disease diagnostic term of Transsexualism (ICD10) $[5,6]$ or previous diagnostic terms such as Gender Identity Disorder (GID) as per the DSM-IV-TR [7]. The prevalence rates quoted in these studies have varied between 0.45 [8] and 23.6 per 100,000 people [9]. More recent prevalence rates of 1:10,000-1:20,000 for males and 1:30,000-1:50,000 for females have been reported [10]. Additionally, another recent study calculated an overall meta-analytical prevalence for Transsexualism of 4.6 in 100,000 people; specifically 6.8 for trans women and 2.6 for trans men [11]. Prevalence studies using the new DSM-5 diagnostic term of Gender Dysphoria are not currently available.

Within clinical services, there have been an increasing number of trans people also presenting with Autism Spectrum Disorder (ASD), which has been of great clinical interest as it has implications for diagnosis and treatment [12, 13]. ASD is defined in the DSM-5 as persistent deficits in social communication and social interaction across multiple contexts. These disturbances must not be better explained by intellectual disability (intellectual 
developmental disorder) or global developmental delay. ASD has a prevalence of 20.6:10,000 with a male to female ratio of 4.2 to 1 [14], although a recent report has suggested that rates may be as high as 1 in 50 for males and 1 in 150 for females [15].

Authors investigating rates of ASD in trans people attending services have found that up to $7.8 \%$ of them report a lifetime prevalence of ASD [12]. However, these findings are contradictory to more recent studies which have shown no differences between trans people and the general population in relation to ASD [16]. The disparity of these findings may be explained by the population selected (adult Vs child), recruitment process (clinics Vs population studies), diagnostic classification system employed (DSM Vs ICD), methodology, design of study (case reports, cohort studies etc.) and tools selected to assess the diagnoses.

Currently, there have been three reviews of the literature pertaining to gender identity, ASD and its co-occurrence. Two of these articles have been non-systematic reviews of the literature [17, 18] and one, a systematic review [19]. Van Schalkwyk [18] simply reviewed the literature between ASD and GD and concluded that due to the limited quantitative research and the conceptual challenge of gender identity, it was impossible to draw any conclusion about the co-occurrence between ASD and Gender Dysphoria, and its aetiology. Robinow [17], who also completed a non-systemic review, set out to explore the aetiology of ASD, transgenderism and paraphilias. He concluded that this co-occurrence could be accounted for by the parent-child relationship and neurobiology. These results should be viewed with caution due to the lack of robust evidence underpinning the conclusions. In contrast, Wood [19] conducted a systematic review to explore the literature pertaining to gender disorders and learning disabilities. Gender disorders included: GID, transsexualism, cross-dressing, transvestism and gender-related sexual disorders. The diagnostic characteristics of GID greatly differ to that of cross-dressing and transvestism. Moreover, treatment and management of these conditions are also vastly different. The authors commented on how there was a dearth of guidance on appropriate treatment and management.

To the authors' knowledge, there is no current and robust systematic review of the literature pertaining to ASD in trans people. It was therefore the aim of this paper to fill this gap within the literature. It is hoped that by obtaining an in-depth and critical overview of the literature, this will aid clinicians when working with trans people with ASD. 


\section{Methodology}

\section{Search strategy}

This systematic review adheres to the guidelines detailed in the PRISMA Statement [20]. The following databases were searched from 1966 to July 2015: Medline/Pubmed, PsycINFO and Embase. Four full-text collections were searched; Science Direct, Ingenta Select, Ovid Full text, and Wiley-Blackwell Interscience. Search terms for trans people (Transsexualism, transgender, Gender Dysphoria, Gender Identity Disorder) and for ASD, (Autistic/Autism Spectrum Disorder, Asperger syndrome, Autism and High Functioning Autism) were combined using the "OR" and “AND” operator. Studies of interest were those that included empirical data on the rates of ASD in trans people or the rates of Gender Dysphoria in people with a diagnosis of ASD. Literature pertaining to treatment options and/or outcomes of trans people with ASD were also included. A second researcher (JA) also completed an independent literature search using the same method described above to increase the validity of the search.

\section{Eligibility criteria}

Studies selected included correlational studies exploring the association between ASD and trans people. Case studies were included, but literature reviews were excluded. Participants either had to have a DSM or ICD diagnosis of ASD or Gender Dysphoria. If an official diagnosis of Gender Dysphoria or ASD was not obtained, then a recognised and validated tool for either ASD or Gender Dysphoria must have been employed. Articles that were considered eligible were written in English and were published in print. Articles in grey literature (including dissertations) or non-peer-reviewed journals were excluded.

\section{Study selection and data collection process}

Articles were screened in three stages: title, abstract, and full text. In the first instance articles were screened by title $(n=58)$ and duplicates were removed $(n=0)$. All articles were then reviewed by abstract for relevance and excluded at this stage if not fulfilling the inclusion criteria. The remaining articles $(n=21)$ were then downloaded for full text review and the reference lists of these articles were also systematically explored. At this stage, two literature reviews of previous studies in trans people and ASD [17, 18] were identified and excluded in accordance to the inclusion criteria. The final sample consisted of 19 studies meeting all eligibility criteria. 
There were two outcome measures of interest: 1) prevalence of ASD in trans people and 2) prevalence of Gender Dysphoria in ASD people. The results section will also review the available literature exploring treatment options and/or outcomes of trans people and ASD. The articles were divided into peer-reviewed cross-sectional studies and case series or case studies.

\section{Summary of the Relevant Studies}

\section{Study Characteristics}

Nineteen relevant studies published between 1966 and July 2015 investigating or describing the relationship between trans people and ASD were considered within this systematic review. Out of the 19 articles, eight were case reports [13, 21, 22, 23, 24, 25, 26, 27] and four were cohort studies. The first cohort study explored the development of gender identity in children with Autism [28], the second established the co-occurrence of ASD and Gender Dysphoria [12], the third attempting to establish predictive factors for autism spectrum traits [29], and the fourth reviewed the overrepresentation of adolescent developmental problems in minors with Gender Dysphoria [30]. Six studies considered within this systematic review were case control studies, two of which employed the AQ to compare autism spectrum traits within a sample of patients with Gender Dysphoria and a control group [16, 31]. A third, investigated sex and gender role orientation in a sample of people with ASD against a matched control group [32]. A fourth, [33] interviewed parents of children presenting with Gender Dysphoria using the Social Responsiveness Scale (SRS) [34] to compare autism spectrum traits between a sample of children with Gender Dysphoria and a control group. A fifth, recruited parents of adolescents with Gender Dysphoria attending services and asked them to complete the Systemising Quotient (SQ) and the Empathy Quotient (EQ) [35]. Finally, the remaining study investigated the rate of obsessional interest and compulsive behavior using questions from the Child Behaviour Checklist (CBCL) [36]. Out of the 19 studies eligible in this systematic review, one was a chart review, which explored rates of gender incongruence as reported by parents on the CBCL in children with different neurodevelopmental disorders, including ASD [37]. All studies used clinical samples. The results are reported for studies involving children and adults separately, in chronological order of publication, to highlight the evolution of the thinking and understanding in the field. 


\section{Publications on Children and Adolescents}

Out of the 19 studies, 12 were concerned with children and adolescents. A summary of all the studies can be found in Tables 1 and 2. Abelson [28] published the first study into the development of gender identity in children with autism. Gender identity was assessed through the Michigan Gender Identity Test (MGIT) [38] with 30 children who had a clinical diagnosis of Autism. The MGIT asks children to sort out photos of boys and girls wearing gender appropriate clothing into categories of boys and girls. The child is also asked to categorize him/herself. The study found a significant positive correlation between increasing mental age and the ability to successfully perform the MGIT, and to a lesser degree increasing chronological age. A significant positive relationship was also shown between MGIT and the Gesell Question ('are you a little boy or a little girl') [39]. Interestingly, three children were unable to answer the Gesell question while correctly completing the MGIT. This indicates that they were able to identify gender in others, but not in themselves. Although the sample size was small, it was the first study to highlight the relationship between gender identity and ASD.

In 2010, De Vries et al. [12] undertook a cohort trial to determine the co-occurrence of GID, as defined in the ICD-10 [5] and ASD, as per DSM-IV-TR [7]. The sample comprised of children $(n=108)$ and adolescents $(n=96)$ who were referred to a national gender identity clinic in the Netherlands and were clinically diagnosed with GID by a senior clinician. The study found that the prevalence of ASD in children with GID was $1.9 \%(n=1)$ and $13 \%(n=6)$ for those with GID Not Otherwise Specified (NOS; disorders of gender identity that are not classifiable as a specific GID) [7]. Interestingly, in six of the children, their Gender Dysphoria alleviated at one year follow up which is fitting with previously published data [40, 41, 42]. The study also found that the prevalence of ASD in all assessed adolescents was 9.4\% $(n=9), 6.5 \%$ in those with GID $(n=5)$ and 37.5\% $(n=3)$ for those with GID NOS. The study concluded that the combined prevalence of ASD within the combined sample was 7.8\% $(n=16), 4.7 \%(n=6)$ in those with GID and $17.0 \%(n=9)$ in GID NOS. This is significantly higher than the prevalence of ASD in the general population as previously reported [43, 15]. De Vries et al. [12] employed a well-validated diagnostic tool for ASD, the Diagnostic Interview for Social and Communication Disorder (DISCO 10) [44]. However, patients were only selected for further examination with the DISCO-10 if the clinician suspected a diagnosis, and therefore possible cases could have been missed by the researcher.

Some researchers have examined specific psychological functions that are characteristic of ASD. For instance Di Ceglie et al. [35] set out to explore systemising and 
empathising (two psychological constructs related to ASD) in adolescents with Gender Dysphoria attending their clinical service. They asked parents of the trans adolescents and of a cis (non-trans) control group to complete the adolescent EQ and the SQ. The authors found that the mean EQ score of trans females and trans males was significantly lower than the control cis females, but similar to control cis males. With regards to the SQ, there was no difference between the trans participants and controls. The study is limited by the small sample size employed $(n=35)$ and poor sampling methods (i.e., trans people were only recruited from one clinical service) which makes the study non generalizable.

Whereas most of the literature is concerned with the presence of ASD among referrals at a gender identity clinic, Strang et al. [37] set out to examine gender variance among children $(n=554)$ and adolescents $(n=147)$ who were primarily diagnosed with a range of neurodevelopment disorders, including ASD. A chart review was conducted and ASD was measured using the ADI/ADI-R [45, 46], which is a detailed parent interview of developmental history and autism symptoms. The Autistic Diagnostic Observation Schedule (ADOS) [47] was also employed; this measure is a structured play and conversational interview to illicit symptoms of ASD. Higher scores indicate more autism. The findings revealed that in comparison to controls, ASD children and adolescents were 7.59 times more likely to express gender variance. However, the CBCL was used to assess gender variance which may have limited the findings as this measure is a parent checklist used to detect emotional and behavioral problems. This study would have benefited from employing a more specific measure of Gender Dysphoria (e.g., Utrecht Gender Dysphoria Scale).

VanderLaan et al. [29] went on to try to establish predictive factors for ASD traits in children $(n=49)$ diagnosed with Gender Dysphoria. The parents of the children were asked to complete the SRS [34] which requires parents to rate social awareness, social cognition, social communication, social motivation and repetitive behaviours of their child. It is a validated tool and also differentiates between mild ASD, high functioning ASD and severe autism. Gender non-conformity was assessed using the Gender Identity Questionnaire for Children (GICQ) [48] which is also a parent report questionnaire. The study found that gender non-conformity and high birth weight were both, independently and combined, a predictive factor for increased ASD traits. Limiting these findings was the reliance on parent report questionnaires, which are not diagnostic tools. Another study using the SRS [33] compared the responses of 166 parents of children presenting with Gender Dysphoria to a previously established SRS mean [49]. This study found that 54.2\% of the children and adolescents within the study scored in the mild/moderate and severe range, indicating 
difficulties in social behaviour. No difference was found in autistic features between natal females and males. The authors concluded that the large number of participants who showed an indication of ASD reflects the poor specificity of the SRS when used with individuals who present with symptoms of Gender Dysphoria.

More recently, VanderLaan et al. [36] recruited children referred to a gender identity clinic, their siblings, and children referred for intense/obsessional interests. Questions 9 (obsession) and 66 (compulsion) where used from the Child Behavior Checklist which is used as a method for identifying problematic behavior in children. A significant increase in obsession was noted in both boys and girls referred to a gender identity clinic when compared to all three other groups. Additionally, a significant increase in compulsion was found for both boys and girls referred to a gender identity clinic compared to both siblings and nongender clinic referred children. This study has a very good level of participants, including children referred to a gender identity clinic $(n=534)$, siblings $(n=419)$ and non-gender clinic referred children ( $\mathrm{n}=1201)$, but relies only on two questions about obsession, which may limit the validity of the findings.

Another recent study [30] reported an overrepresentation of severe adolescent developmental disorders in children under the care of a Finnish gender identity clinic over a period of two years. Twelve children (26\%) in their total sample had previously been diagnosed with ASD according to a psychiatric case note review. No re-establishment of the diagnosis of ASD was made which limits the validity of the findings.

There have also been several case studies describing ASD in children and adolescents with Gender Dysphoria. For example, Williams et al. [21] discusses 'Cross-Gender Preoccupation' in two natal male autistic children (five and three years old). Both children showed more interest in feminine toys then masculine toys and enjoyed cross-dressing. For the eldest, after a one year follow up, the cross-dressing and preference for feminine toys remained, despite improvement in their function. The authors felt this was a likely manifestation of the children's autism, but did query GID. A year later Landén and Rasmussen [22] reported the case of a 14 year old natal girl with a diagnosis of ASD and Obsessive Compulsive Disorder (OCD) who at the age of eight, started to claim to be a boy. The child presented with clear gender dysphoric symptoms and these continued at follow up. Mukaddes [23] described two natal boys with a diagnosis of high functioning autism who showed persistent gender identity incongruence, that continued throughout a four year follow up period. And finally, Perera et al. [24] reported the case of a 20 year old natal female who was followed up since the age of nine with diagnoses of Asperger's and OCD and who 
presented with GID. They reported a continuation of the OCD symptoms but a lessening of the GID symptoms at follow ups.

Overall, the literature in children and adolescents with Gender Dysphoria and ASD is very limited and relies primarily on case reports. Whilst case studies may provide and in depth discussion about the complex interplay between ASD and symptoms of Gender Dysphoria (and in some cases other disorders), they are limited by the fact that they cannot be generalised. Nevertheless, robust studies conducted in this area suggest that the prevalence rates of ASD in children and adolescents with symptoms of Gender Dysphoria is considerably higher than in the general population.

\section{Publications on Adults}

Out of the 19 articles, seven were concerned with adults. A summary of all the studies can be found in Tables 2 and 3. Two case control studies [16, 31] employed the AQ [50] to determine whether trans people had more autistic traits compared to a general and ASD population. Both studies recruited patients from a gender identity clinic service. The AQ, which is validated, is a screening instrument and not a diagnostic tool for ASD. Scoring highly on the AQ predicts a higher likelihood of the presence of ASD as opposed to being diagnostic of ASD. Jones et al. [31] found that trans men scored significantly higher on the AQ than trans females and control females. The AQ was significantly higher for all trans people compared to the general population. The study also found that homosexual trans women had significantly higher AQ levels than heterosexual trans women. Interestingly, Pasterski et al. [16] who employed a very similar design, found no significant difference between any of the trans people or general population groups. The difference may be related to the control group, as Pasterski et al. [16] used previously published figures [51] instead of recruited controls.

A case control study by Bejerot \& Erikson [32] explored sex and gender role orientation using the Swedish modification of the Bem Sex Role Inventory [52]. People diagnosed with ASD $(n=50)$ were compared to a matched control group $(n=53)$ (according to natal gender, age, education and having children). Atypical gender identity was reported to be significantly higher in people with ASD (11.5\%) compared to controls (3.6\%). This difference lost statistical significance when the group was divided by natal gender. Both natal men and natal women in the ASD group were found to present with significantly less masculinity compared to controls. The study explores an interesting area, although no formal diagnosis of Gender Dysphoria or Transsexualism was made. A further potential limitation is 
that the study stereotypes what constitutes masculine and feminine ideas and behavior according to the Bem Sex Role Inventory.

Once again, there is lack of scientific research in this area and most of the relevant publications consist of case studies. For example, Kraemer et al. [53] described the case of a 35 years old natal female with a diagnosis Asperger Syndrome who also fulfilled the DSMIV diagnostic criteria for GID. The authors' believed that GID was developed secondary to adopting male emotional and cognitive traits due to the Asperger Syndrome, rather than a true co-occurrence. Following treatment for GID, good social functioning was reported. The same year Gallucci et al. [25] reported the case of a 41 years old natal male with a diagnosis of High Functioning Autism or Asperger Syndrome who presented with symptoms of Gender Dysphoria. The authors discussed whether the gender incongruence was part of OCD or were part of a diagnosis of Gender Dysphoria.

Lemaire et al. [36] described a 23 years old natal female with GID, ASD and a borderline IQ level. The case study described not only the clinical presentation, but also the treatment. The authors suggested that prior to consideration for cross-sex hormone treatment and/or surgical intervention, speech and communication therapy should be completed. Similarly, Jacobs et al. [13] discussed the cases of a 29 year and 18 year old natal male, both diagnosed with ASD. The oldest, presented with gender dysphoric feelings, but little wish to undergo a social role transition. The 19 year old presented with clear gender dysphoric feelings and felt they had transitioned in their mind but had failed to make external changes to their presentation. Therefore, those around them struggled to recognise them as female.

In summary, as per the literature in children and adolescents, there have also been a limited amount of publications investigating the relationship between ASD in adults with Gender Dysphoria. The studies that have been conducted appear to suggest that, in some cases, there is a co-occurrence between symptoms of Gender Dysphoria and ASD, although the studies are more limited and less robust than those in the child and adolescent literature. Most of these studies describe prevalence rates and no studies specifically discussed the influence of any of the diagnoses on treatment outcomes.

\section{Insert Tables 1, 2 and 3 around here}

\section{Discussion}

The aim of this systematic review was to critically describe the literature regarding the co-occurrence of Gender Dysphoria and ASD. Although the literature was limited, 
especially in relation to adults, overall, this systematic review found a high prevalence of ASD in people with Gender Dysphoria attending clinical services.

There are several potential explanations for the co-occurrence between Gender Dysphoria and ASD. Some authors [16, 31, 32] have discussed whether the EMB theory [54] plays a role in this association. This theory postulates that the brains of typical males and females have two domains: empathising and systemising. The empathising component includes having an appropriate emotional reaction to another person's thoughts and feelings. Systemising is the drive to analyse or construct systems. Within the general population, typical females are thought to display more empathising and less systemising traits compared to typical males. Studies assessing these brain domains in people (both males and females) with ASD have found an extreme version of the male brain, where systemising is above average and empathy is reduced $[55,56]$. It has been hypothesised that high levels of fetal testosterone are responsible for the EMB [57]. This theory could therefore account for the cooccurrence of Gender Dysphoria and ASD in trans males (natal females), but not trans females [22]. This research alone highlights how the co-occurrence between ASD and Gender Dysphoria is likely to be complex and that there may be different mechanism underlying ASD and Gender Dysphoria in both males and females [16].

It has also been hypothesised that sex hormones could account for the association between ASD and Gender Dysphoria. Autistic traits displayed during childhood have been positively related to foetal testosterone $[54,58,59]$. Children diagnosed with ASD, especially girls, have shown elevated androgens [60] and report more androgen related disorders [61]. Similarly, the main mechanism responsible for gender identity involves a direct effect [or lack] of testosterone on the developing human brain, as seen in certain conditions. For instance, people with intersex and related conditions who have been exposed to prenatal androgen levels which are at variance to either their genotype, (male or female sex chromosomes) or their assigned birth gender are much more likely to change from the gender they were assigned at birth, than persons without these conditions [62, 63, 64, 65]. However, although the above theory may suggest that natal females with ASD present with elevated testosterone levels, an association between high levels of testosterone in females and Gender Dysphoria have not been found. Bejerot et al. [32] also felt that the androgen hypothesis of ASD did not explain the androgynous physical features of people diagnosed with ASD; therefore they set out to assess physical measures, related to androgen influence, in adults with and without ASD. The authors found that women diagnosed with ASD had elevated serum testosterone levels and they displayed more masculine traits than women without 
ASD. Additionally, men with ASD displayed more feminine characteristics, than men without ASD. The authors concluded that rather than being a disorder characterised by masculinisation in both genders, ASD seems to be a gender defiant disorder and therefore gender incongruence should be expected in ASD patients.

The co-occurrence of ASD and Gender Dysphoria may also be a reflection of the impairment in empathy that is characteristics of people with ASD. Many people with ASD report that they are puzzled by how to respond to another person's emotions [66]. For example, they may be able to see that someone is crying, deduce that they are sad or upset, but not know why, or how to comfort them. This impairment in empathy may facilitate them "coming out" and pursuing their true believes, in this case transitioning to their experienced gender, without being prevented by societal prejudices or without being influenced by how other people feel about their decision.

It must also be considered that other factors are also likely to contribute to the aetiology of ASD, Gender Dysphoria and its co-occurrence. For instance, Robinow [17] claimed that the presence of Gender Dysphoria later in life can be traced back to difficulties within the mother-child relationship during the first two years of the child's life. They suggested that issues within this relationship can be responsible for the activation (or deactivation) of specific genes. For instance, Fonagy and Target [67] implied that without the capacity for Theory of Mind (which is thought to be lacking and universal in people with ASD [68]) attachment bonds do not form, however attachment bonds early in life are crucial to the development of gender identity [69].

An issue with all hypotheses that attempt to account for the co-occurrence of Gender Dysphoria and ASD, is specificity. It needs to be determined as to whether elevated traits of ASD are specific to patients with Gender Dysphoria, or a characteristic of this clinical population more generally [70].

\section{Limitations of the current literature}

The limited literature in this field does not allow for clear conclusions regarding the prevalence or the aetiology of ASD in trans people. Studies using good diagnostic procedures and/or tools are usually limited by the small numbers of subjects, whereas when the number of cases increases, the validity of the diagnosis of ASD and/or Gender Dysphoria is limited. The stronger and more reliable studies have been conducted with children, showing an overall higher prevalence of ASD among people referred to gender identity clinic services [12]. The increased prevalence rates reported may be due to a number of reasons. For 
instance, the number of referrals being received by gender identity clinic services in North America and Europe has increased substantially over the years [71, 72]. The increase in prevalence over the years is likely to be due to several factors: the increased visibility of trans people in the media, which likely contributes to at least a partial de-stigmatisation of being trans [71]; the wide availability of information on the internet about trans people, which also likely contributes to de-stigmatisation [71]; the increased awareness of the availability of biomedical treatment $[2,3,4]$; and the development of societal tolerance towards trans individuals [73]. Perhaps trans individuals, with ASD, have less reservation to seek referral to gender identity clinic services, as explained above, and therefore constitute a relative overrepresentation within clinical samples.

One limitation that remains is the fact that much of the research has been conducted with those who have been referred to gender identity clinic. Such a sample will be comparably smaller to querying a diagnosis of Gender Dysphoria within the larger ASD population. These studies therefore at best present the prevalence of ASD within those wishing assessment and/or treatment for their Gender Dysphoria.

Little has been written about the treatment and potential difficulties therein within the trans population presenting with both previously diagnosed and undiagnosed ASD. There have not been, to the authors' knowledge, any reports of outcomes and/or increased rates of dissatisfaction, de-transition or postoperative regret in this population. Nevertheless, there remains ongoing clinical concern regarding misdiagnosis, informed consent and/or potential treatment difficulties relating to cross-sex hormone treatment and sex reassignment surgeries.

\section{Clinical implications for the co-occurrence between ASD and Gender Dysphoria}

The assessment of Gender Dysphoria in individuals with ASD can become more complex due to some of the difficulties experienced by those with ASD. These could include difficulties in communication, shared psychological conceptualisation and in the building of a therapeutic relationship between the patient and the clinician. Specific examples include concerns of obsessional interests, concrete thinking and the reduced or lack of Theory of Mind in patients with ASD and the subsequent potential lack of two way gender recognition (both one's own internal thought of and experience of their gender, as well as the recognition of how others experience the expression of their gender). Another consideration is the specialist and time consuming nature of recognising the presence of and making the diagnosis of either or both Gender Dysphoria and ASD, especially when being trained and experienced in both domains is rare. Social role transition and functional components often required prior 
to starting treatment, such as having a social and/or occupational function can make navigating the treatment pathway more difficult. These difficulties become further compounded if the clinician has little experience of working with people with ASD. All of this can leave experienced and skilled clinicians feeling less confident about their assessment and treatment. This will have implications for the treatment of patients with both Gender Dysphoria and ASD, ranging from an incomplete assessment, uncertainty about whether to commence potentially irreversible treatment with cross-sex hormones and gender-related surgical procedures, through to a fear of potential adverse outcomes. Risk adverse clinicians may undertreat patients. In turn, this may leave the patient feeling misunderstood, under supported and not receiving necessary treatment. Further experience of assessing and treating the Gender Dysphoria of those with ASD may start to allay much of the above. However, only good quality research about assessment procedures, any adaptations to the treatment pathway required and robust treatment outcome evaluation, will improve this.

Overall, there remain significant gaps in the understanding of the aetiology, potential co-occurrence Gender Dysphoria and ASD, appropriate assessment and treatment and outcome of treatment of trans people with ASD. Further research is required for educational and clinical purposes. 


\section{References}

1. American Psychiatric Association. Diagnostic and Statistical Manual of Mental Disorders-5 (DSM-5). Washington DC: American Psychiatric Association, 2013.

2. Ahmad S, Barrett J, Beaini AY, Bouman WP, Davies A, Greener HM, Lenihan P, Lorimer S, Murjan S, Richards C, Seal LJ, Stradins L. Gender dysphoria services: a guide for general practitioners and other healthcare staff. Sex Relation Ther 2013; 28: 173-186.

3. Coleman E, Bockting W, Botzer M, Cohen-Kettenis P, DeCuypere G, Feldman J, Fraser L, Green J, Knudson G, Meyer WJ, Monstrey S, Adler RK, Brown GR, Devor AH, Ehrbar R, Ettner R, Eyler E, Garofalo R, Karasic D H, Lev AI, Mayer G, Meyer-Bahlburg H, Hall BP, Pfaefflin F, Rachlin K, Robinson B, Schechter LS, Tangpricha V, van Trotsenburg M, Vitale A, Winter S, Whittle S, Wylie KR, Zucker K. Standards of Care for the Health of Transsexual, Transgender, and Gender-Nonconforming People, Version 7. Int J Transgend 2012; 13: 165-232.

4. Wylie K, Barrett J, Besser M, Bouman WP, Bridgman M, Clayton A, Green R, Hamilton M, Hines M, Ivbijaro G, Khoosal D, Lawrence A, Lenihan P, Loewenthal D, Ralph D, Reed T, Stevens J, Terry T, Thom B, Thornton J, Walsh D, Ward D, Coleman E, Di Ceglie D, Martin E, McGarry P, Messenger A, Reid R, Sethi S, Sutcliffe P, Wilson D, Carr S, Davies D, Dean T, Ellis M, Ferguson B, Skinner D, Williams V, Brechin S, Lucey J, Rathbone M. Good Practice Guidelines for the Assessment and Treatment of Adults with Gender Dysphoria. Sex Relation Ther 2012; 29: 154-214.

5. World Health Organisation. The ICD-10 Classification of Mental and Behaviour Disorders; tenth addition. Geneva: World Health Organisation, 1992.

6. Drescher J, Cohen-Kettenis P, Winter S. Minding the body: situating gender identity diagnoses in the ICD-11. Int Rev Psychiarty 2012; 24: 568-577.

7. American Psychiatric Association. Diagnostic and Statistical Manual of Mental DisordersIV-TR (DSM-IV-TR). Washington DC: American Psychiatric Association, 2000.

8. $\quad$ Wålinder J. Incidence and sex ratio of transsexualism in Sweden. Br J Psychiatry 1971; 119: 195-6.

9. Tsoi WF. The prevalence of transsexualism is Singapore. Acta Psychiatrica Scandinavica 1988; 78: 501-504.

10. Zucker KJ, Lawrence AA. Epidemiology of Gender Identity Disorder: Recommendations for Standards of Care for the World Professional Association for Transgender Health. Int J Transgend 2009; 11: 8-18.

11. Arcelus J, Bouman WP, Van De Noortgate W, Claes L, Witcomb GL, Fernandez-Aranda F. Systematic review and meta-analysis of prevalence studies in transsexualism. European Psychiatry 2015, e-pub ahead of print.

12. De Vries AL, Noens IL, Cohen-Kettenis PT, van Berchelaer-Onnes IA, Doreleijers TA. Autism Spectrum Disorders in Gender Dysphoric Children and Adolescents. J Autism Dev Disorder 2010; 40: 930-936.

13. Jacobs LA, Rachlin K, Erickson-Schroth L, Jansson A. Gender Dysphoria and Co-Occuring Autistism Spectrum Disorders: Review, Case Examples and Treatment Considerations. LGBT Health, 2014; 2. 
14. Van Caenegem E, Wierck K, Elaut E, Buysse A, Dewaele A, Van Nieuwerburgh F, De Cuypere G, T'Sjoen G. Prevalence of Gender Nonconformity in Flanders, Belgium. Arch Sex Behav 2015; 44: 1281-7.

15. Bloomberg SJ, Bramlet MD, Kogan MD, Schieve LA, Jones JR, Lu MC. Changes in Prevalence of Parent-Reported Autism Spectrum Disorder in School-aged U.S. Children 2007-2012. National Health Statistics Reports, 2013; 65: 1-11.

16. Pasterski V, Gilligan L, Curtis R. Traits of Autism Spectrum Disorders in Adults with Gender Dysphoria. Arch Sex Behav, 2014; 43: 387-393.

17. Robinow O. Paraphilia and transgenderism: a connection with Asperger's Disorder? Sexual Relation Ther 2009; 24: 143-151.

18. Van Schalkwyk GI, Klingensmith K, Volkmar FR. Gender Identity and Autism Spectrum Disorders. Yale J Biol Med 2015; 88: 81-83.

19. Wood E, Halder N. Gender disorders in learning disability- a systematic review. Tizard Learning Disability Rev 2014; 19: 158-165.

20. Moher D, Liberati A, Tetzlaff J, Altman DG, The PRISMA Group. Preferred reporting items for systematic reviews and meta-analyses: The PRISMA Statement. PLoS Medicine 2006: 6.

21. Williams PG, Allard A, Sears L. Case Study: Cross-Gender Preoccupations in Two Male Children with Autism. J Autism Dev Disorders 1996; 26: 635-642.

22. Landén M, Rasmussen P. Gender Identity Disorder in a Girl with Autism - A Case Report. Eur Child Adoles Psy 1997; 6: 170-173.

23. Mukaddes NM. Gender Identity Problems in Autistic Children. Child Care Hlth Dev 2002; 24: 529-532.

24. Perera H, Gadambanathan T, Weerasiri S. Gender Identity Disorder Presenting in a Girl with Asperger's Disorder and Obsessive Compulsive Disorder. Ceylon Med J 2003; 48: 5758.

25. Galluci G, Hackerman F, Schmidt CW. Gender Identity Disorder in an Adult Male with Asperger's Syndrome. Sex Disabil 2005; 23: 35-40.

26. Lemaire M, Thomazeau, B, Bonnet-Brilhault F. Gender Identity Disorder and Autism Spectrum Disorder in a 23 year old Female. Arch Sex Behav 2014; 43: 395-398.

27. Kraemer B, Delsignore A, Gundelfinger R, Schnyder U, Hepp U. Comorbidity of Asperger Syndrome and Gender Identity Disorder. Eur Child Adol Psy2005; 14: 292-296.

28. Abelson AG. The Development of Gender Identity in the Autistic Child. Child Care Hlth Dev, 1981; 7: 347-356.

29. VanderLaan DP, Leef JH, Wood H, Hughes SK, Zucker KJ. Autism Spectrum Disorder Risk Factors and Autistic Traits in Gender Dysphoric Children. J Autism Dev Disorders, 2015; 6: 1742-1750.

30. Kaltiala-Heino R, Sumia M, Työläjärvi M, Lindberg N. Two years of gender identity service for minors: overrepresentation of natal girls with severe problems in adolescent development. Child and Adolesc Ment Health 2015.

31. Jones RM, Wheelwright S, Farrell K, Martin E, Green R, Di Ceglie D, Baron-Cohen S. Brief Report: Female-To-Male Transsexual People and Autistic Traits. J Autism Dev Disorders, 2012; 42: 301-306.

32. Bejerot S, Eriksson JM. Sexuality and Gender Role in Autism Spectrum Disorder: A Case Control Study. PLOS One, 2014; 9: 1-9. 
33. Skagerberg E, Di Ceglie D, Carmichael P. Brief Report: Autistic Features in Children and Adolescents with Gender Dysphoria. Journal of Autism and Developmental Disorders 2015.

34. Constantino JN, Gruber CP. Social Responsiveness Scale (SRS). Los Angeles, CA: Western Psychological Services, 2005.

35. Di Ceglie D, Skagerberg E, Baron-Cohen S, Auyeung B. Empathising and Systemising in Adolescents with Gender Dysphoria. Opticon, 2014; 16: 1-8.

36. VanderLaan DP, Postema L, Wood H, Singh D, Fantus S, Hyun J, Leef J, Bradley SJ, Zucker KJ. Do Children with Gender Dysphoria have Intense/Obsessional Interests?J Sex Res 2015; 52: 213-219.

37. Strang FJ, Kenworthy L, Dominska A, Sokoloff J, Kenealy EL, Berl M, Walsh K, Menvielle E, Slesaransky-Poe G, Kim K, Luong-Tran C, Meagher H, Wallace LG. Increased Gender Variance in Autism Spectrum Disorders and Attention Deficit Hyperactivity Disorder. Arch Sex Behav 2014; 43: 1525-33.

38. Paluszny M, Beit-Hallahmi B, Catford JC, Cooley R, Dull C, Guiora AZ. Gender Identity and its Measurement in Young Children. Compr Psychiat, 1973; 14: 281-290.

39. Gesell A, Halverson HM, Thompson H, Ilg FL, Costner BM, Ames LB, Amatruda CS. The First Five Years of Life: A Guide to the Study of the Preschool Child. New York: Harper, 1940.

40. Zucker KJ, Bradley SJ. Gender identity disorder and psychosexual problems in children and adolescents. New York: Guilford, 1995.

41. Cohen-Kettenis P, Pfäfflin F. Transgenderism and intersexuality in childhood and adolescence. Thousand Oaks, London, New Delhi: SAGE, 2003.

42. Wallien MSC, Cohen-Kettenis PT. Psychosexual outcomes of gender dysphoric children. J Am Acad Child Adolesc Psychiatry 2008; 47: 1413-23.

43. Fombonne E. Epidemiology of Autistic Disorder and other Pervasive Developmental Disorders. J Clin Psychiat 2005; 66: 3-8.

44. Wing L, Leekam SR, Libby SJ, Gould J, Larcombe M. The diagnostic interview for social and communication disorders: Background, inter-rater reliability and clinical use. J Child Psychol Psychiat 2002; 43: 307-325.

45. Le Couteur A, Rutter M, Lord C, Rios P, Robertson S, Holdgrafer M, McLennan J. Autism diagnostic interview: a standardized investigator-based instrument. J Autism Dev Disorder, 1989; 19: 363-87.

46. Lord C, Rutter M, Le Couteur A. Autism Diagnostic Interview-Revised: A revised version of a Diagnostic Interview for Caregivers of Individuals with Possible Pervasive Developmental Disorders. J Autism Dev Disorders 1994; 24.

47. Lord C, Rutter M, DiLavore P, Risi S. Autism Diagnostic Observation Schedule. ADOS Manual. Los Angeles: Western Psychological Services, 2002.

48. Johnson L L, Bradley SJ, Birkenfeld-Adams AS, Kuksis MAR, Maing DM, Mitchell JN, Zucker KJ. A parent-report Gender Identity Questionnaire for Children. Arch Sex Behav, 2005; 33: 105-116.

49. Wigham S, McConachie H, Tandos J, Le Couteur A, Gateshead Millenium Study core team. The reliability and validity of the Social Responsiveness Scale in a UK general child population. Res Dev Disabil 2012; 33: 944-950.

50. Baron-Cohen S, Richler J, Bisarya D, Gurunathan N, Wheelwright S. The Autistic Spectrum Quotient (AQ): Evidence from Asperger Syndrome/high functioning Autism, males and females, scientists and mathematicians. J Autism Dev Disorders 2001; 31: 5-17. 
51. Wheelwright S, Baron-Cohen S, Goldenfield N, Delaney J, Fine DRS. Predicting Autistic Spectrum Quotient from Systemizing Quotient-Revised and Empathy Quotient. J Autism Dev Disorders, 2006; 1079, 47-56.

52. Bem S. The Measurement of Psychological Androgyny. J Consult Clin Psychol 1974; 42: 155-162.

53. Kraemer B, Delsignore A, Gundelfinger R, Schnyder U, Hepp U. Comorbidity of Asperger Syndrome and Gender Identity Disorder. Euro Child Adolesc Psychiatry 2005; 14: 292-296.

54. Baron-Cohen S. The Extreme Male Brain Theory of Autism. Trend Cogn Sci 2002; 6: 248254.

55. Baron-Cohen S, Lombardo MV, Auyeung B, Ashwin E, Chakrabarti B, Knickmeyer R, Why are autism spectrum conditions more prevalent in males? PLoS Biol 2011; 9.

56. Baron-Cohen S, Cassidy S, Auyeung B, Allison C, Achoukhi M, Robertson S, Pohl A, Lai M. Attenuation of Typical Sex Differences in 800 Adults with Autism vs. 3,900 Controls. PLOS ONE 2014; 9.

57. Auyeung B, Baron-Cohen S, Ashwin E, Knickmeyer R, Taylor K, Hackett G. Fetal testosterone and autistic traits. Brit J Psychol 2009; 100: 1-22.

58. Baron-Cohen S, Lutchmaya S, Knickmeyer RC. Prenatal Testosterone in Mind: Amniotic Fluid Studies. Cambridge, MA: MIT Press, 2004.

59. Knickmeyer R, Baron-Cohen S, Raggatt P, Taylor K, Hackett G. Fetal testosterone and empathy. Horm Behav 2006; 49: 282-292.

60. Geier AD, Geier RM. A prospective assessment of androgen levels in patients with autistic spectrum disorders: biochemical underpinnings and suggested therapies. Neuroendocrinol Letters, 2007; 28: 565-573.

61. Ingudomnukul E, Baron-Cohen S, Wheelwright S, Knickmeyer R. Elevated rates of testosterone-related disorders in women with autism spectrum conditions. Horm Behav 2007; 51: 597-604.

62. Cohen-Kettenis PT. Gender Change in 46,XY Persons with 5 $\alpha$-Reductase-2 Deficiency and 17 $\beta$-Hydroxysteroid Dehydrogenase-3 Deficiency. Arch Sex Behav 2005; 34: 399-410.

63. Dessens AB, Slijper FME, Drop SLS. Gender Dysphoria and Gender Change in Chromosomal Females with Congenital Adrenal Hyperplasia. Arch Sex Behav, 2005; 34: 389-397.

64. Mazur T. Gender Dysphoria and Gender Change in Androgen Insensitivity or Micropenis. Arch Sex Behav 2005; 34: 411-421.

65. Meyer-Bahlburg HFL. Gender Identity Outcome in Female-Raised 46,XY Persons with Penile Agenesis, Cloacal Exstrophy of the Bladder, or Penile Ablation. Arch Sex Behav, 2005; 34: 423-438.

66. Grandin T. Thinking in Pictures. Vancouver, WA: Vintage Books, 1996.

67. Fonagy P, Target M. Early Intervention and the Development of Self-Regulation. Psychoanal Inq 2002; 22: 307-335.

68. Baron-Cohen S. Theory of mind and autism: A fifteen year review. In Baron-Cohen S, Tager-Flusberg H, Cohen DJ. Understanding other minds: Perspectives from developmental cognitive neuroscience (2nd ed.). Oxford University Press: New York, 2000, pp 3-30.

69. Coates S. Developmental research on childhood gender identity disorder. In Peter Fonagy, Rainer Krause, \& Bohleber Leutzinger (Eds.), Identity, gender and sexuality, 150 years after Freud. London: International Psychoanalytic Association, 2006. 
70. Zucker KJ, Leef JH, Wood H, Hughes SK, Wasserman L, \& Vanderlaan DP. LinkedIn? On the relation between gender dysphoria and traits of autism spectrum disorder in children. Presentation International Academy of Sex Research. Toronto, Canada, August 2015.

71. Aitken M, Steensma TD, Blanchard R, VanderLaan DP, Wood H, Fuentes A, Spegg C, Wasserman L, Ames M, Lindsay Fitzsimmons C, Leef JH, Lishak V, Reim E, Takagi A, Vinik J, Wreford J, Cohen-Kettenis PT, de Vries ALC, Kreukels BPC, Zucker KJ. Evidence for an altered sex ratio in clinic-referred adolescents with gender dysphoria. J Sex Med. 2015;12: 756-763.

72. De Vries ALC, Kreukels BPC, T’Sjoen G, Ålgars M, Mattila A. Increase of referrals to gender identity clinics: A European trend? In: Transgender Healthcare in Europe. Book of Abstract. pp10. Ghent, Belgium: European Professional Association of Transgender Health (EPATH). 2015.Retrieved online from http://epath.eu/wpcontent/uploads/2014/07/EPATH-2015-Book-of-Abstracts.pdf on 8th April 2015.

73. Keuzenkamp S, Kuyper L. Acceptance of LGBT individuals in the Netherlands 2013. The Hague: The Netherlands Institute of Social Research (ED), 2013. 
Table 1: Study Characteristics in Children and Adolescents

\begin{tabular}{|c|c|c|c|c|c|c|}
\hline Date & Author & $\begin{array}{l}\text { Type } \\
\text { of } \\
\text { Study }\end{array}$ & Number of Pts & Recruitment & $\begin{array}{l}\text { Diagnostic or Screening } \\
\text { Tools }\end{array}$ & Results \\
\hline 1981 & Abelson & Cohort & 30 & $\begin{array}{l}\text { Patients with } \\
\text { previously } \\
\text { established ASD. }\end{array}$ & $\begin{array}{ll}\text { - } & \text { Michigan Gender } \\
& \text { Identity Test (MGIT). } \\
\text { - } & \text { Alpern-Boll } \\
& \text { Developmental Profile. } \\
\text { - } & \text { Gesell Question. }\end{array}$ & $\begin{array}{l}\text { +ve Correlation between } \\
\text { mental age and successful } \\
\text { MGIT. +ve correlation } \\
\text { between MGIT and Gesell } \\
\text { question. }\end{array}$ \\
\hline 2010 & $\begin{array}{l}\text { De Vries et } \\
\text { al. }\end{array}$ & Cohort & 231 & $\begin{array}{l}\text { Children and } \\
\text { adolescents referred } \\
\text { to gender identity } \\
\text { clinic service. }\end{array}$ & $\begin{array}{l}\text { Gender Dysphoria: } \\
\text { - } \quad \text { Clinical assessment } \\
\text { via DSM-TR and ICD } \\
10 \text { diagnostic criteria. } \\
\text { ASD: } \\
\text { - Initial Clinician } \\
\text { - } \quad \text { DCreening for cases. } \\
\text { DISCO-10. }\end{array}$ & $\begin{array}{l}\text { Incidence of } 7.8 \% \text { of ASD in } \\
\text { total study. Incidence of } 4.7 \% \\
\text { of ASD with Gender } \\
\text { Dysphoria. Incidence of } 17 \% \\
\text { of ASD with Gender } \\
\text { Dysphoria NOS. }\end{array}$ \\
\hline 2014 & $\begin{array}{l}\text { Di Ceglie et } \\
\text { al. }\end{array}$ & $\begin{array}{l}\text { Case } \\
\text { control }\end{array}$ & 347 & $\begin{array}{l}\text { Parents of } \\
\text { adolescents who } \\
\text { were diagnosed with } \\
\text { Gender Dysphoria or } \\
\text { a control group }\end{array}$ & $\begin{array}{l}\text { Gender Dysphoria: } \\
\text { - Clinical assessment via } \\
\text { DSM-IV criteria. } \\
\text { ASD: } \\
\text { - Empathy Quotient } \\
\text { (EQ) and the } \\
\text { Systemising Quotient } \\
\text { (SQ) }\end{array}$ & $\begin{array}{l}\text { - The mean EQ score of the } \\
\text { trans males and trans females } \\
\text { was significantly lower than } \\
\text { the control females but similar } \\
\text { to the control males. } \\
\text { The mean score on the SQ did } \\
\text { not differ between the trans } \\
\text { participants and the controls. }\end{array}$ \\
\hline 2014 & Strang et al. & $\begin{array}{l}\text { Case } \\
\text { notes } \\
\text { review }\end{array}$ & 554 & $\begin{array}{l}\text { Children and } \\
\text { adolescents } \\
\text { diagnosed with } \\
\text { ASD, ADHD, a } \\
\text { neurodevelopment } \\
\text { disorder, controls }\end{array}$ & $\begin{array}{l}\text { Gender Dysphoria: } \\
\text { - Child Behaviour } \\
\text { Checklist (CBCL) } \\
\text { ASD: } \\
\text { - ADI/ADI-R }\end{array}$ & $\begin{array}{l}\text { - Incidence 5.4\% of gender } \\
\text { variance in ASD. } \\
\text { - } \quad \text { Incidence of } 4.8 \% \text { of gender } \\
\text { variance in ADHD. } \\
\text { - } \quad \text { Incidence of } 1.7 \% \text { of gender } \\
\text { variance in neurodevelopment }\end{array}$ \\
\hline
\end{tabular}




\begin{tabular}{|c|c|c|c|c|c|c|}
\hline & & & & $\begin{array}{l}\text { (with none of the } \\
\text { above disorders) and } \\
\text { normative data from } \\
\text { the CBCL. }\end{array}$ & - $\mathrm{ADOS}$ & $\begin{array}{l}\text { group. Incidence of } 0.07 \% \text { of } \\
\text { gender variance in controls. }\end{array}$ \\
\hline 2014 & $\begin{array}{l}\text { VanderLaan } \\
\text { et al. }\end{array}$ & Cohort & 49 & $\begin{array}{l}\text { Children with } \\
\text { Gender Dysphoria at } \\
\text { gender identity clinic } \\
\text { service. }\end{array}$ & $\begin{array}{ll}\text { - } & \text { Social Responsiveness } \\
\text { Scale (SRS). } \\
\text { - } & \text { Gender Identity } \\
& \text { Questionnaire for } \\
& \text { Children (GIQC). } \\
\text { - } & \text { Wechsler Intelligence } \\
& \text { Scale for Children } \\
\text { - } & \text { CBCL. }\end{array}$ & $\begin{array}{l}\text { - High birth weight predicted } \\
\text { increased ASD traits. Increased } \\
\text { gender non-conformity } \\
\text { predicted increased ASD traits. } \\
\text { - Both high birth weight and } \\
\text { increased gender non- } \\
\text { conformity predicted increased } \\
\text { ASD traits. }\end{array}$ \\
\hline 2015 & $\begin{array}{l}\text { VanderLaan } \\
\text { et al. }\end{array}$ & $\begin{array}{l}\text { Case } \\
\text { control }\end{array}$ & $\begin{array}{l}\text { Gender referred } \\
\mathrm{n}=534, \\
\text { Siblings } n=419 \text {, } \\
\text { non-gender } \\
\text { referred } n=1201\end{array}$ & $\begin{array}{l}\text { Children referred to } \\
\text { gender identity clinic } \\
\text { service and their } \\
\text { siblings. Children } \\
\text { referred for } \\
\text { obsessional interests. }\end{array}$ & $\begin{array}{l}\text { - } \text { CBCL: question } 9 \text { and } \\
66 \text { (both related to } \\
\text { obsessionality). }\end{array}$ & $\begin{array}{l}\text { Significant increase in } \\
\text { obsessionality in boys and girls } \\
\text { referred to gender identity } \\
\text { clinic service compared to all } \\
\text { other groups. }\end{array}$ \\
\hline 2015 & $\begin{array}{l}\text { Skagerberg } \\
\text { et al. }\end{array}$ & $\begin{array}{l}\text { Case } \\
\text { Control }\end{array}$ & 166 parents & $\begin{array}{l}\text { Parents of children } \\
\text { presenting with } \\
\text { Gender Dysphoria. }\end{array}$ & $\begin{array}{ll}\text { - } & \text { SRS } \\
\text { - } & \text { Case note review for } \\
\text { previous diagnosis of } \\
\text { ASD. } \\
\text { - Clinical assessment of } \\
\text { Gender Dysphoria. }\end{array}$ & $\begin{array}{l}\text { - No significant difference in } \\
\text { mean SRS scores between case } \\
\text { or control. } \\
\text { No significant difference in } \\
\text { mean SRS subscale scores } \\
\text { between case or control. }\end{array}$ \\
\hline 2015 & $\begin{array}{l}\text { Kaltiala- } \\
\text { Heino et al. }\end{array}$ & Cohort & 47 & $\begin{array}{l}\text { Children under the } \\
\text { care of a gender } \\
\text { identity clinic } \\
\text { service. }\end{array}$ & $\begin{array}{l}\text { - } \text { Case note review for } \\
\text { previous diagnosis of } \\
\text { ASD. } \\
\text { - Clinical assessment of } \\
\text { Gender Dysphoria. }\end{array}$ & $\begin{array}{l}\text { 26\% those who had } \\
\text { experienced Gender Dysphoria } \\
\text { had previous diagnosis of } \\
\text { ASD. }\end{array}$ \\
\hline
\end{tabular}


Table 2: Study Characteristics of Case Studies

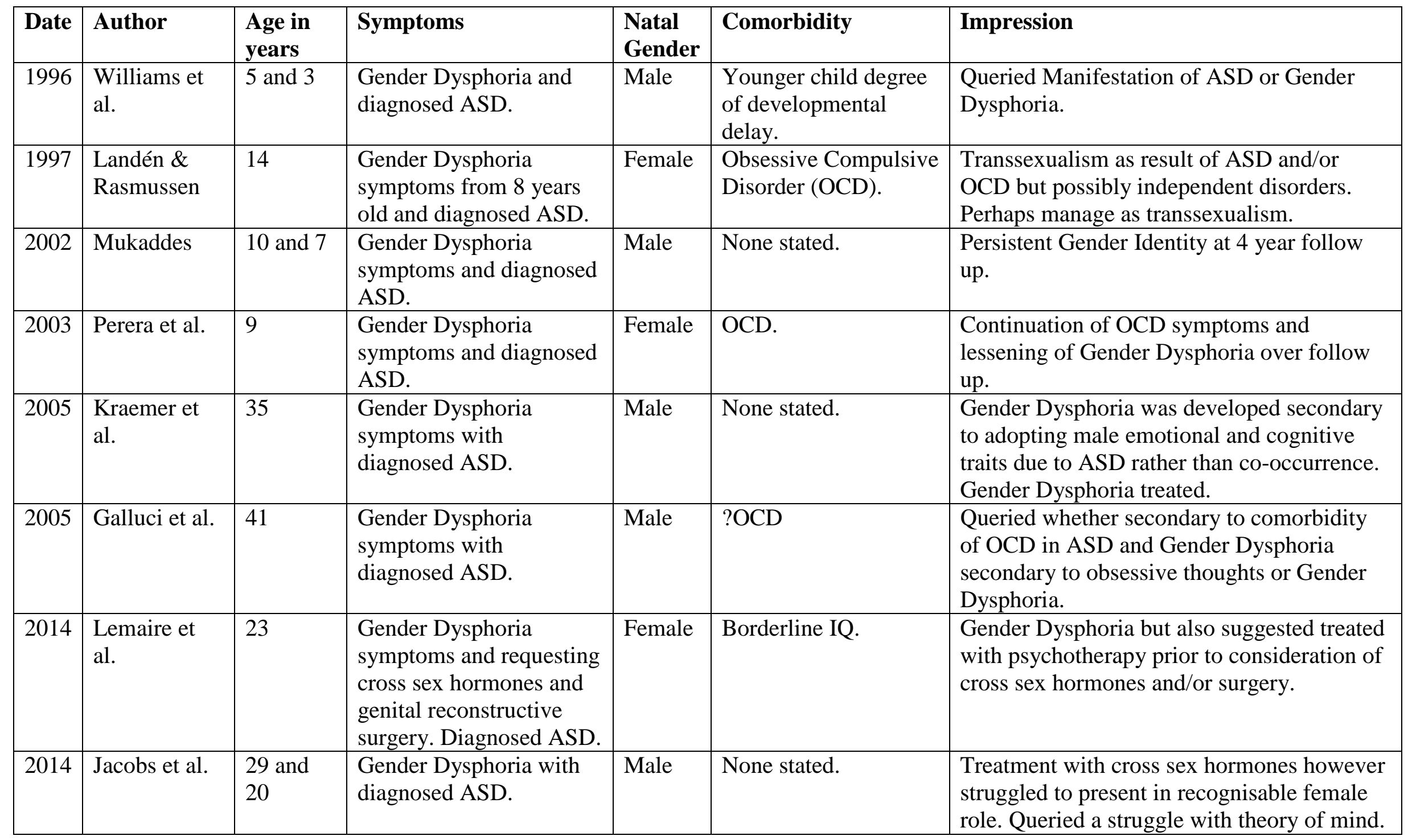


Table 3: Study Characteristics in Adults

\begin{tabular}{|c|c|c|c|c|c|c|}
\hline Date & Author & $\begin{array}{l}\text { Type of } \\
\text { Study }\end{array}$ & Number of Pts & Recruitment & $\begin{array}{l}\text { Diagnostic or } \\
\text { Screening Tools }\end{array}$ & Results \\
\hline 2012 & Jones et al. & $\begin{array}{l}\text { Case } \\
\text { control }\end{array}$ & $\begin{array}{l}\text { Transmen } n=61 \\
\text { Transwomen } \\
n=128 \\
\text { Control males } \\
n=76 \\
\text { Control females } \\
n=98 \\
\text { Patients with ASD } \\
n=125 \text { (this is } \\
\text { taken from another } \\
\text { previous study } \\
\text { Wheelwright et al } \\
\text { 2006) }\end{array}$ & $\begin{array}{l}\text { NHS Gender Identity } \\
\text { Clinic and website. }\end{array}$ & $\begin{array}{ll}\text { - } & \text { Autistic } \\
\text { Quotient (AQ). } \\
\text { - } & \text { ASD diagnosed } \\
\text { in Wheelwright } \\
\text { et al by DSM } \\
\text { IV criteria. }\end{array}$ & $\begin{array}{l}\text { Trans men significantly } \\
\text { higher mean on the AQ } \\
\text { than trans females and } \\
\text { cis females. }\end{array}$ \\
\hline 2014 & $\begin{array}{l}\text { Pasterski et } \\
\text { al. }\end{array}$ & $\begin{array}{l}\text { Case } \\
\text { Control }\end{array}$ & $\begin{array}{l}\text { Transwoman } n=63 \\
\text { Transmen } n=28\end{array}$ & $\begin{array}{l}\text { Private Gender } \\
\text { Identity Clinic. }\end{array}$ & - $\mathrm{AQ}$. & $\begin{array}{l}\text { Mean AQ increased in } \\
\text { transgendered patients } \\
\text { but not significantly. }\end{array}$ \\
\hline 2014 & $\begin{array}{l}\text { Bejerot \& } \\
\text { Eriksson }\end{array}$ & $\begin{array}{l}\text { Case } \\
\text { control }\end{array}$ & $\begin{array}{l}\text { ASD } n=50 \\
\text { Neurotypical } n=53\end{array}$ & $\begin{array}{l}\text { ASD } \\
\text { - } \quad \text { Outpatient tertiary } \\
\text { adult ASD clinic. } \\
\text { - Community based } \\
\text { centre for adult } \\
\text { with ASD. } \\
\text { - Website for adults } \\
\text { with ASD. } \\
\text { Control } \\
\text { - } \quad \text { Matched controls }\end{array}$ & $\begin{array}{ll}\text { - } & \text { ADOS. } \\
\text { Wechsler } \\
\text { Intelligence } \\
\text { Scale } \\
\text { - } \text { MF Scale (a } \\
\text { Validated } \\
\text { Swedish } \\
\text { modification of } \\
\text { the Bem Sex } \\
\text { Role Inventory; } \\
\text { BSRI). }\end{array}$ & $\begin{array}{l}\text { 'Masculinity' was } \\
\text { significantly lesser in } \\
\text { ASD than controls. }\end{array}$ \\
\hline
\end{tabular}

